\title{
Effect of Latanoprost Eye Drops on Central Corneal Thickness in North Indian Population
}

\author{
Dr. Atul Kumar Singh \\ Department of Ophthalmology, 12 Air Force Hospital, Gorakhpur, Uttar Pradesh, India
}

\begin{abstract}
To study the effect of Topical Latanoprost eye drops in patients with POAG on central corneal thickness. There are reports on literature to see the effect on CCT in patients of POAG, who is already in Latanoprost eye drop; however, there are very few studies to see the effect of these drops in CCT in Indian eyes.
\end{abstract}

Keywords: Latanoprost eye drops, Central corneal thickness, North Indian eyes, glaucoma, intraocular pressure

\section{Introduction}

Glaucoma is the commonest cause of blindness and it has been estimated that in the beginning of this millennium, 66.8 million individuals in the world would have glaucoma, and of which $60 \%$ will be in Asia ${ }^{1}$. In the countries like India, glaucoma is emerging as a major cause of blindness and adds to already a severe backlog of needles blind due to cataract. The predominant form of primary glaucoma is open angle. Recently well designed population based survey have been conducted in India, which have highlighted the relative prevalence of glaucoma and consequent visual impairment. The Andhra Pradesh eye study ${ }^{2}$ had reported prevalence of POAG to be $2.52 \%$ in those aged 50 years or more. Intra ocular Pressure (IOP) measurement is one of the key steps in the diagnosis and monitoring of glaucoma. To prevent further damage from glaucoma, Target pressure must be achieved. However Central Corneal Thickness (CCT) is a major variable in calculating the IOP. A linear correlation between Central Corneal Thickness (CCT) and IOP measured by Goldman Applanation Tonometer (GAT) has been described by several groups, suggesting that Goldman Applanation Tonometry results in under estimation in thin corneas and overestimation in the thick corneas ${ }^{3}$.The main modality of treatment of glaucoma is by pressure lowering drops and now a day's Latanoprost is the most common used eye drops in POAG. Latanoprost is a prostaglandin analogue. Latanoprost $0.005 \%$ decreases IOP by increasing outflow of aqueous humor through uveoscleral pathways ${ }^{4}$.This study is carried out to see the effect on CCT of topical Latanoprost eye drops and to see its whether increase or decrease in CCT actually affects the IOP measurements.

\section{Materials and Method}

After taking the approval of the Hospital ethical committee, this study is carried out in one of the eye centre of North India_by single ophthalmologist

\section{Inclusion criteria were}

- Patients of primary open angle glaucoma

- Age-30-60 year

- Clear media

\section{The exclusion criteria were}

- Corrected visual acuity worse than $6 / 12$ in either eye

- Corneal abnormalities

- Active Old iridocylitis

- Any History of contact lens use

- Concomitant use of ocular medications of anti glaucoma to control IOP

- Allergy to any topical eye drops

After taking written informed consent from patients, detailed history was taken followed by complete examination, including assessment of best corrected visual acuity (BCVA), anterior segment examination with slit lamp, baseline IOP measurement with Goldman applanation tonometer and fundus examination with $90 \mathrm{D}$ lens. Humphrey Standard Perimetry was performed. CCT was measured in all patients by single Ophthalmologist using ultrasound pachymeter .Three consecutive readings were taken and mean was considered as a baseline. After confirming the diagnosis of POAG, patients were put on Latanoprost eye drops $(0.005 \%)$ with the instruction to keep bottles at temp of 2 to 8 degrees. Patients were strictly told to put eye drops at $9 \mathrm{PM}$ with single drop only. Patients were advised to follow up at one month and three months. All the patients are requested to come at a specific time around $9 \mathrm{AM}$ in follow to avoid any diurnal variations and any another factor.

\section{Results}

A total of 13 eyes of 12 subjects (one has both eyes POAG) were observed to determine the effect of topical $0.005 \%$ Latanoprost on central corneal thickness in patients with Primary Open Angle Glaucoma. Age distribution was given in Table 1

Table 1: Showing age distribution

\begin{tabular}{|c|c|}
\hline AGE & Patients \\
\hline 40 to 50 years & 01 \\
\hline 50 to 60 years & 05 \\
\hline 60 to 70 years & 06 \\
\hline
\end{tabular}

Baseline CCT was analyzed in these subjects and results are shown in Table -2 


\section{International Journal of Science and Research (IJSR) \\ ISSN (Online): 2319-7064}

Index Copernicus Value (2013): 6.14 | Impact Factor (2015): 6.391

Table 2: Baseline CCT

\begin{tabular}{|c|c|c|}
\hline CCT & RE & LE \\
\hline$<500$ MICRONS & 03 & 01 \\
\hline 500-525 MICRONS & 04 & 03 \\
\hline$>525$ MICRONS & 01 & 01 \\
\hline
\end{tabular}

Mean baseline CCT level of right eyes was 513 microns and of left eyes 508 microns.

After three months patients were again evaluates for CCT and mean CCT was calculated and compared with baseline as shown in Table 3.

\begin{tabular}{|c|c|c|}
\hline Eye & Base Line & After 3 Months \\
\hline Right & 513 & 509 \\
\hline Left & 508 & 505 \\
\hline
\end{tabular}

$\mathrm{P}$ value has been calculated for pre-treatment and posttreatment CCT using T-test and is found to be less than 0.0001 . By conventional criteria this difference is considered to be extremely statistically significant $(\mathrm{P}<0.0001)$.

\section{Discussion}

Glaucoma is said to be a silent killer of vision. It is slowly progressive in nature and remains asymptomatic. The aim of glaucoma management is to preserve the visual functions and quality of life of the individual. There are a number of risk factors for glaucoma, but currently IOP is the only modifiable risk factor that can be used to prevent progressive optic neuropathy. By achieving a target IOP rate of visual field loss over a period of 5 years can be close to zero ${ }^{5}$.Any anti glaucoma medication must have 24 hour IOP control with the minimum concentration, as well as minimal local and systemic side effects. Latanoprost is a prostaglandin analogue with once a dose regime and minimal number of side effects in long term use $\mathrm{e}^{6}$. It is reported that the action of latanoprost starts with first two weeks maximizes in six weeks and then stabilizes without short term and long term drift ${ }^{7}$.There are number of studies to see the amount of IOP lowering effect in different population and it ranges from $25 \%$ to $32 \%, 9$. In our study Latanoprost demonstrated a decrease in CCT of treated eyes close to $0.77 \%$ in both eyes. These results are quite similar to different studies of different countries ${ }^{10,11}$. However, some studies have shown that long term use of Latanoprost actually increases the $\mathrm{CCT}^{12}$. Some researchers have found that an increase in the concentration of free calcium and the activation of the protein Kinase $\mathrm{C}$ of the corneal stroma is the reason for the increase of corneal thickness in their studied patients ${ }^{13}$.The cause of decrease in CCT with latanoprost was supposed to be due to corneal stroma fibroblasts contraction. However, they do not show such a reaction in the presence of timolol ${ }^{14}$. These all studies have shown the importance of taking CCT in each visit of patients. Other variables that may be affected by long term use of Latanoprost is ACD (anterior chamber Depth) ${ }^{15}$. In a very recent study authors have demonstrated decreased number of keratocytes as well as CCT on patients receiving Prostaglandins analogue ${ }^{16}$. Our study has some limitation as study subjects are very few in number and duration of follow up was also less. These results were not compared with any another control group on any other topical anti glaucoma drugs. However, this is the first kind of study on north Indian population to see effect of Latanoprost on CCT. A large multi centre study is required to see its effect on CCT on long term follow up especially in Indian eyes.

\section{Conclusion}

Our study demonstrates decrease in CCT of patients, who were on topical Latanoprost eye drops. So Latanoprost therapy requires careful monitoring while treating patients with primary open angle glaucoma and CCT must be recorded in every patient on follow up. However, it seems that the amount of reduction in CCT does not likely to cause any effect in calculating IOP in follow up.

\section{References}

[1] Quigley HA .The number of people with glaucoma world wide.Br j ophthalmology 1996

[2] Dandona et al .Open angle glaucoma in urban population in south India.Ophthalmology 2000, 107, 17021709

[3] Kniestedt, Christoph. Correlation Between Intraocular Pressure, Central Corneal Thickness, Stage of Glaucoma, and Demographic Patient Data: Prospective Analysis of Biophysical Parameters in Tertiary Glaucoma Practice Populations. Journal of Glaucoma. April 2006, volume 15, Issue 2, P 91-97

[4] Carol B Toris et al, Update on the Mechanism of Action of Topical Prostaglandins for Intraocular Pressure Reduction. Survey Of Ophthalmology .November 2008. Volume 53, Issue 6, Supplement, Pages S107S120

[5] Anders Heijl, MD, PhD; M. Cristina Leske, MD, MPH; Bo Bengtsson, MD, PhD; Leslie Hyman, PhD; Boel Bengtsson, PhD; Mohamed Hussein, PhD; Early Manifest Glaucoma Trial Group. Reduction of Intraocular Pressure and Glaucoma .Progression Results From the Early Manifest Glaucoma Trial. Clinical Sciences October 2002

[6] Novack GD, O'Donnell MJ, Molloy DW. New glaucoma medications in the geriatric population: Efficacy and safety. J Am Geriatr Soc. 2002; 50: 95662.

[7] Camras CB. Comparison of latanoprost and timolol in patients with ocular hypertension and glaucoma: a sixmonth masked, multicenter trial in the United States. The United States Latanoprost Study Group. Ophthalmology 1996;103:138-47.

[8] Watson PG, The Latanoprost Study group. Latanoprost: two Years' experience of its use in United Kingdom. Ophthalmology 1998;105:82-87.

[9] $1 \mathrm{~m}$ A, Widengard, Latanoprost: Experience of 2-year treatment in Scandinavia. Acta Ophthalmol Scand 2000;78:71-76.

[10] Sen E, et al. (2008). Comparison of the Effects of Latanoprost and Bimatoprost on Central Corneal Thickness.J Glaucoma, 17(5), 389-402

[11] Brandt JD, Gordon MO, Baiser JA, et al. (2008). Changes in Central Corneal Thickness over Time.Ophthalmology, 11, 1550- 6

[12] Tsikripis P, Papaconstantinou D, Koutsandrea C, Apostolopoulos M, Georgalas I. (2013). The effect of

\section{Volume 5 Issue 7, July 2016 www.ijsr.net}




\section{International Journal of Science and Research (IJSR) \\ ISSN (Online): 2319-7064}

Index Copernicus Value (2013): 6.14 | Impact Factor (2015): 6.391

prostaglandin analogues on the biomechanical properties and central thickness of the cornea of patients with open-angle glaucoma: a 3-year study on 108 eyes. Drug Design, Development and Therapy, 7, 1149-56

[13] Bafa M, Georgopoulos G, Mihas C, Stavrakas P, Papaconstantinou D, Vergados I. (2011). The effect of prostaglandin analogues on central corneal thickness of patients with chronic open-angle glaucoma: a 2-year study on 129 eyes. ActaOphthalmol, 89, 448-51.

[14] Liu Y, et al. (2006). Effect of anti-glaucoma drugs on collagen gel contraction mediated by human corneal fibroblasts.J Glaucoma, 15, 255-9

[15] Gutierrez-Ortiz C, Teus MA, Bolivar G.: Short term effects of Latanoprost on anterior chamber depth in patients with glaucoma or ocular hypertension. Invest Ophthalmol. 2006;47:4856-4859

[16] Sibel Kocabeyoglu, Mehmet C Mocan, Murat Irkec. Decreased keratocyte density and central corneal thickness in primary open-angle glaucoma patients undergoing treatment with topical prostaglandin analogues.Indian Journal Of Ophthalmolgy. 2015 Volume: 63, Issue: 1 Page : 15-19 